\title{
PREGUNTAS A JUAN M. DIAZ DE GUEREÑU SOBRE JUAN LARREA
}

\author{
POR \\ ARMANDO ZARATE \\ University of Vermont
}

Entre los días 9 y 13 de julio de 1985 se celebraron, simultáneamente en Bilbao y San Sebastián, las Primeras Jornadas Internacionales Juan Larrea (1895-1980), en las que participaron profesores universitarios, escritores e intelectuales de América y de España. El resultado fue también la publicación de las actas o volumen Al Amor de Larrea, que reúnen todos los trabajos presentados durante las Jornadas. Dispuestos a conocer el alcance que tuvieron ambas empresas, en tal oportunidad le preguntamos al concertante y editor Díaz de Guereñu:

A. Z.: Como crítico literario, ¿qué inquietudes te acercaron a la obra de Jian Larrea?

D. G.: Yo conocí a Larrea por simple curiosidad de lector, como supongo suele suceder. Venía interesándome desde hacía tiempo por ese fenómeno variopinto y fructífero de las venguardias y me había topado ya alguna vez con su nombre cuando cayó en mis manos un ejemplar de Versión Celeste, de modo que inicié su lectura ya con una cierta expectación. Sin embargo, sus poemas desbordaron con mucho todas mis predisposiciones, con su enorme caudal imaginativo y su capacidad evocadora; leerlos es una continua sorpresa. Luego, claro, vino la larga búsqueda y la lectura de sus obras en prosa - prácticamente inasequibles entonces en España, por tratarse de ediciones americanas dispersas y porque Larrea había estado prohibido por la censura-, obras que venían a continuar lógicamente las perspectivas abiertas por su poesía. Sólo después de esa lectura en amplitud surgió la idea de estudiarlo como crítico: era una amplísima vía abierta y paradójicamente casi virgen, pues, aparte algunos trabajos de David Bary, apenas si se le había de- 
dicado atención crítica. La elección de la poesía como primer objeto de análisis me pareció obvia, pues ofrece en forma condensada una importante cantidad de problemas de expresión y contenido, por sí mismos tentadores y que, además, son presupuestos de su obra en prosa posterior. Es un trabajo inagotable en el que aún estoy empezando.

\section{ción? \\ A. Z.: ¿Qué libros del poeta y ensayista Larrea son de tu predilec-}

D. G.: Es bien difícil, ciertamente, distinguir en Larrea al poeta y al ensayista, porque es ensayista sólo en cuanto que poeta y su lógica de prosista y crítico, tan estricta, es una lógica poética. No obstante, si separamos el verso de la prosa, el primero no nos causa muchos problemas de selección, pues los poemas de Larrea sólo se han recogido en un libro: Versión Celeste. La edición de Barral de 1970, agotada hace tiempo, era, por lo demás, una edición parcial, una selección que ni siquiera recogía todos los poemas publicados en revistas. Ya es tiempo, realmente, de recopilar y dar a la luz la poesía completa, incluyendo todo el material inédito o disperso que existe; sería una obra reducida pero densa. En cuanto a la prosa, la selección es más complicada, porque Larrea publicó mucho y bueno. Siguiendo la idea anterior de que existe un íntimo enlace entre las concepciones poéticas de Larrea y su visión toda del mundo, que se desarrolla en su prosa, eligiría tal vez un libro que tiene a la poesía por tema nuclear: Al amor de Vallejo (Ed. PreTextos, Valencia, 1980), que recoge sus ensayos vallejianos más significativos y muestra bien a las claras esa filiación poética, en visión, tema y modo de expresión, de su prosa. O recurriría a uno de sus primeros libros, Rendición de Espíritu (Cuadernos Americanos, México, 1943), que es también, aunque en otro sentido, germen de los que siguieron. Si en aquél podemos encontrar los cimientos de toda su construcción mental, en este segundo tenemos el primer plano, el primer desarrollo.

A. Z.: Según tu modo de ver, ¿qué lugar ocupa Larrea entre los poetas de su generación?

D. G.: Un lugar peculiar, desde luego. El propio Larrea, cuando se le preguntaba respecto a la generación del 27 , respondía siempre que él no tuvo nada que ver con el grupo y que sólo mantenía contacto, por razones de amistad, con Gerardo Diego. $Y$, en efecto, su residencia en París desde 1926, el uso del francés incluso como lengua para la ex- 
presión poética, obedecían a su deseo de distanciarse de un ambiente literario que consideraba trivial, «sin solución puesto que sin problemas», como le escribe a Diego. No hay más que observar el tono de provocación de su revista Favorables Paris Poema, dirigida contra ese ambiente. Es preciso recordar, al respecto, que su primer y único intento de integrarse en los cenáculos literarios se produjo en 1919, entre las estridencias, riñas y mediocridades de los «ultraístas»; su juicio permaneció desde entonces prácticamente idéntico. En cambio, en un sentido inverso, tenemos testimonios escritos y reiterados de que varios miembros de la generación admiraban sin reservas su obra poética, tan escasamente divulgada. Es el caso, por supuesto, de Diego, pero también de Bergamín, Alberti, Cernuda y hasta Guillén. Creo que hoy ya se tiende a admitir que Larrea ocupó con respecto a éstos un puesto de avanzada, en cuestiones formales y también en preocupaciones de fondo. Es seguro que, a medida que se vayan conociendo más en detalle las relaciones entre los poetas del 27 se irá descubriendo que no existía esa cohesión fraternal que el mito pretende y que autores aparentemente marginales al grupo, como Larrea, estaban más presentes de lo que parece.

A. Z.: Juan Larrea ha sido secretario fundador de Cuadernos Americanos y del Instituto del Nuevo Mundo en la Córdoba argentina. Sabemos que ningún estudioso de origen español se ha dedicado con más fervor a la causa o el mensaje del continente americano. ¿Es justo este juicio?

D. G.: Es justo, en efecto. Larrea forma parte, en realidad, de esa parte de la intelectualidad, de ese conjunto incluso, que el franquismo expulsó de la península con la derrota republicana. Es la España peregrina, por recobrar al nombre de la primera revista del exilio en que participó Larrea. Entre esos exiliados, como siglos antes entre los sefarditas expulsados de su tierra, resurgió con fuerza inusitada el sentimiento de la Hispanidad, envuelto a menudo en un poderoso aliento utópico nacido, probablemente, por contraste con la terrible distopía que aplastó por la fuerza de las armas a la República. Basta recordar las obras de los León Felipe, Bergamín o Eugenio Imaz en aquella época, en aquella revista. La peculiaridad de Larrea radica en que su sentimiento utópico estaba tan desarrollado ya, era tan consustancial a su modo de entender el universo que no podía conformarse con la añoranza y se imponía un salto adelante. Conviene tener en cuenta, además, que la utopía de Larrea se apoyaba, en buena medida, en su vivencia jubilosa de América durante su viaje al Perú en 1930-1931. Así, nada más lógico que 
-enlazando con la literatura del descubrimiento, llena también de maravilla y esperanza - trasvasar, como lo hizo Larrea, al Nuevo Mundo geográfico su Nuevo Mundo utópico e identificar el exilio republicano con una auténtica transmigración del alma de la Hispanidad a un nuevo ámbito, abierto a todas las posibilidades, en contraste con una España sangrientamente inmolada y momificada por la dictadura.

A. Z.: Durante las Jornadas, ¿cuáles fueron las inclinaciones de los poetas o los críticos sobre el pensamiento de Larrea?

$D$. G.: Las perspectivas e intereses han sido extremadamente variados. No podía ser de otro modo, puesto que se reunían por primera vez en torno a su obra personas de varias generaciones - desde Gerardo Diego, compañero suyo en las lides poéticas, hasta los más jóvenes, que ni siquiera le conocimos en vida - y de formación o dedicaciones culturales muy diversas. En realidad, creo que se estudiaron, o se insinuaron al menos, casi todas las facetas y obras importantes de Larrea: el poeta, el crítico, el arqueólogo o el pensador utópico. Aludimos entonces a los «millares de aristas» de Larrea, por utilizar una expresión suya, que son, claro está, inabarcables en un encuentro de ese tipo. Pero esa variedad de abordes es enriquecedora, creo, y ofrece como mínimo un atisbo de la amplitud de su obra. Tal vez podrían agruparse las aportaciones en dos grandes bloques: por un lado, quienes le conocieron más de cerca o tuvieron un trato más íntimo con él, que ofrecieron perspectivas, digamos, internas a su obra y a su humanidad, por simpatía; por otro, gentes que en general no le conocimos, de formación universitaria, que nos inclinamos por análisis más distanciados de la obra, desde perspectivas críticas o científicas. Estos dos acercamientos son perceptibles, me parece, en el libro.

\section{A. Z.: ¿Destacarias algún aspecto en particular de las Jornadas?}

D. G.: Lo más singular, desde mi punto de vista, fue el hecho mismo de que gentes tan distintas y distantes, incluso por su origen geográfico, se reunieran al reclamo de la obra de un autor tan poco conocido y convocados desde una Universidad periférica, la Facultad de Deusto en San Sebastián en la que estoy integrado, para un proyecto muy modesto en su inicio. Yo fui, lo confieso, el primer sorprendido y creo que eso dice mucho de la capacidad de seducción de la obra y personalidad de Larrea. Sí me gustaría, con todo, destacar la participación en las Jornadas de tres poetas de renombre, Gabriel Celaya, Germán Bleiberg y 
Gerardo Diego, una nueva confirmación de aquella definición de «poeta de poetas» que alguien dio de Larrea. E1 caso de Diego es especial y pienso que merece subrayarse la dedicación, la perenne lealtad a Larrea de un poeta de su talla. Diego ofreció además para su publicación documentos inéditos propios y de Larrea, cartas y poemas de juventud, abriendo de nuevo con enorme generosidad caminos a la difusión de su obra.

A. Z.: Además de publicarse "Al amor de Larrea» ¿qué otros éxitos se han tenido?

D. G.: El objetivo fundamental que presidió la celebración de las Jornadas fue el de reintegrar la obra de Larrea al lugar que le corresponde en nuestra historia cultural. Larrea es el paradigma del eterno exiliado, en buena medida por propia voluntad, como se ha señalado: París, luego América, fueron sede en su momento de un esfuerzo incansable de búsqueda en profundidad de sí mismo. Lo cual no obsta para que ocupe, por derecho, un lugar en nuestra cultura. Es responsabilidad nuestra que así suceda. La celebración de las Jornadas y la publicación de sus Actas en $\mathrm{Al}$ amor de Larrea fueron un intento de aunar voluntades en este sentido. De sus logros sólo pueden dar fe los libros o números monográficos que se le han dedicado o se le dedicarán desde entonces o la difusión ulterior de su obra entre nosotros. El tiempo dirá, pero hay algunas buenas perspectivas: por ejemplo, en una Antología comentada de la poesía española contemporánea de próxima edición, Larrea tiene su lugar junto a los más grandes poetas de nuestro siglo.

\section{A. Z.: ¿Cuátes son los nuevos proyectos? ¿Cuándo se formalizarán} las nuevas jornadas?

$D$. G.: En lo que a mis proyectos personales se refiere, actualmente preparo con Enrique Cordero de Ciria, secretario personal de Gerardo Diego, una edición de las cartas de Larrea a este último. Se trata de un conjunto documental impresionante, en volumen - cerca de un millar de cuartillas manuscritas- y significación, pues constituyen una auténtica autobiografía personal, intelectual y poética. Esperamos poder publicar también la otra mitad de la correspondencia, las cartas de Diego a Larrea, lo que multiplicaría aún el interés del trabajo, pero falta por concretar esa posibilidad. De cualquier modo, aquella parte de la correspondencia por sí sola justifica el esfuerzo. En cuanto a unas nuevas Jornadas Juan Larrea, no hay ningún proyecto definido todavía; creo que conviene 
dejar un tiempo para que aquel esfuerzo vaya concretándose en nuevos resultados y los trabajos que allí se apuntaban maduren. Entretanto, celebraremos esta primavera del 86, también en San Sebastián, unas Segundas Jornadas Internacionales dedicadas a Blas de Otero que esperamos habrán de ser una aportación importante en el estudio de este poeta. De hecho, las Jornadas dedicadas a Larrea fueron también el punto de partida para estos encuentros, que se pretende se sucedan con una periodicidad bianual. 